\title{
Advanced information technologies in education
}

\author{
Jaradat Idrisova ${ }^{1, *}$, Saydmagomed Alikhadzhiev ${ }^{1}$, and Natalia Moiseenko ${ }^{2}$ \\ ${ }^{1}$ Chechen State University, Grozny, Russia \\ ${ }^{2}$ Grozny State Oil University named after academician M.D. Millionshchikova, Grozny, Russia
}

\begin{abstract}
Modern mankind has joined the general historical process called computerization. In contrast to the industrial society, in which the main thing was the production of material goods, in today's post-industrial society the production of information becomes the main activity (by information we mean knowledge as information about people, objects, facts, events), phenomena and processes, regardless of their form representation that can be recorded on a tangible medium), and this process is called computerization (hence the term - information society). Such a shift in emphasis is caused, on the one hand, by the fact that humanity is aware of the limited natural (natural) resources of its habitat, and on the other hand, by the emergence of global problems (for example, energy, the environment), a solution that is impossible with previous methods. Information is becoming the main resource for the development of the world community and significantly affects the development of other industries and spheres of life: science, technology, social spheres (cultural communication between people, education). The core values of the information society are:knowledge; -qualification; - independent thinking; -the ability to work with information and make informed decisions based on it; - awareness not only in a narrow professional field, but also in related fields.
\end{abstract}

\section{Introduction}

The ability to think independently, based on knowledge and experience, is valued much higher than just erudition or possession of a wide range of knowledge without the ability to apply this knowledge to solve specific problems. Competence comes to the fore. Thus, the Council of Europe has identified the following basic or key competencies (competence is what gives rise to skills, actions) that determine the degree of development of society:

1. Responsibility for participation in joint social and political decision-making.

2. Ability to coexist with people of other cultures, languages, religions in a monocultural society, based on an understanding of differences, mutual understanding.

3. Possession of oral and written communication, which plays an important role in social and professional activities. Those who do not possess this skill are in danger of falling out of the life of society.

4. Ability to master new technologies.

5. Ability to be critical (to distinguish truth from falsehood) to information and advertising disseminated through media channels.

\footnotetext{
* Corresponding author: J120712@yandex.ru
} 
6. Ability is lifelong learning as a foundation for continuing education in work life as well as in personal and social life. Thus, the concept of "computerization of society" can be defined as a global social process, the peculiarity of which is that the dominant type of activity in the sphere of social production is the collection, accumulation, production, processing, transfer and use of information carried out on the basis of microprocessors and computer technologies. as well as through various means of information exchange [3].

Informatization is a system of the following interrelated processes:

- informational - separation and presentation of all socially significant information in the form available for storage, processing and transmission by electronic means;

- cognitive - the formation and preservation of an integral information model of the world, which allows society to carry out proactive dynamic regulation of its development at all levels: from individual activity to the functioning of public institutions; material construction of a global infrastructure for electronic means of storing, processing and transmitting information [5].

A special role in the computerization of society belongs to the education system, since education acts, on the one hand, as a consumer of information, on the other, as a creator of new information technologies (through highly qualified personnel). Since the ability to work with information is becoming one of the priorities for a modern person, the education system is designed to train the student's ability to think critically, starting from school (critical thinking is characterized by knowledge, understanding, application, analysis, synthesis, assessment). Education, flexibility of thinking, the ability to navigate a huge flow of information become significant values for a person throughout his life. These values are also significant for society, since the rapid development of technologies in all areas of science, culture, production involves the use of the creative potential of educated people not only in the field of management, but also for servicing technologies [3].

Thus, the informatization of education is considered as one of the main directions of informatization of society. Computerization of education refers to the process of providing the education sector with methodology, technologies and practice for the development and optimal use of modern IR technologies aimed at realizing the psychological and pedagogical goals of education and training and health care. friendly conditions are used more comfortably and conveniently.

The word technology in translation from Greek means art, dexterity, the ability to do things, which means an action or process, that is, a series of actions aimed at achieving a goal. The process is carried out using various means and methods.

Previously, the concept of technology referred only to the sphere of material production and meant a set of means and methods of processing, manufacturing, changing the state, properties, form of raw materials or materials. Technologies always change the quality or the initial state of the material in order to obtain the final material product. Since, as already mentioned, the production of information is becoming the main type of human activity, the term "information technology" appeared, which is understood as a process that uses a set of tools and methods for collecting, transferring, accumulating, processing, storing, presenting and using data (primary information) to obtain new qualitative information about the state of an object, phenomenon or process (information product) [1].

Advanced IT - information technology:

- Mathematical and computer modeling;

- DB and knowledge;

- Expert and intelligent systems;

- Tools, technologies for planning and management using spreadsheets;

- E-mail and telecommunications;

- Integrated packages of applied programs and environments;

- Means, methods and technologies of computer graphics and animation; 
- Means, methods and technologies of multimedia;

- Hypertext technologies and WWW-technologies;

- CASE technologies, etc.

The introduction of information technology in schools can be carried out in the following areas:

- Replacement of textbooks with e-books and tablets.

- Teaching students to program.

- Conducting psychological and pedagogical testing.

- Implementation of interactive testing.

- Using additional education programs to gain in-depth knowledge or broaden your horizons.

- Distance learning.

- Creation of digital natural science laboratories.

- Implementation of new management and supervision systems: in the field of personnel, classroom accounting, accounting.

Schoolchildren can use information technologies not only in the classroom, but also in the framework of extracurricular work. For example, schools can create robotics clubs to train children in the practical application of technology.

The Digital Technology for Teachers study (which surveyed 2,700 teachers) found that the vast majority of teachers use a variety of digital equipment in the classroom, such as a projector, laptop, interactive whiteboard, tablet, and computer. This is $98 \%$ of the surveyed teachers in grades 1-11 (but it should be noted that the survey was conducted online, which could have influenced its results). $34 \%$ of teachers use digital achievement in every lesson.

The advantages of using information technology in school practice are:

- Mastering by schoolchildren of computer technologies, without which it is impossible to imagine their adult life.

- Easier assimilation of the school curriculum, thanks to multimedia.

- Improving academic performance.

- The ability to access educational programs when a student is sick.

- The ability to regulate the pace of learning, taking into account the individual and cognitive characteristics of the student.

Development of flexibility of thinking, goal-setting skills, self-education and selfdiscipline.

The disadvantages of introducing information technology for schoolchildren may be as follows:

They can distract students. Research shows that smartphones and gadgets distract children from the learning process. Although monotonous lessons without any digital technology also do not contribute to concentration.

Technology negatively affects students' communication skills and social interactions. Children who constantly "sit" in gadgets have a reduced ability for live communication. Lack of speech activity and practice in the formulation and expression of personal opinions, the influence of clip thinking can negatively affect the skills of independent thinking. [one]

Technology can provoke students to shy away from completing assignments on their own (for example, they can simply copy an abstract from the network).

Not all students have equal access to technology resources. Parents cannot buy a tablet, smartphone or laptop for all schoolchildren.

Information on the web is not always of high quality and verified. Unfiltered information can be psychologically harmful to a child.

Increased eye strain on students.

Benefits of implementing information technology in schools: 
The opportunity to make lessons interesting and dynamic, providing for a variety of educational activities: getting to know new training programs, slide shows, presentations, multimedia albums.

Increasing the motivation and involvement of students in the educational process and improving their academic performance.

Ability to build materials based on an evidence base.

Saving the teacher's time to explain and consolidate new material.

Simplification of the teacher's work, automation of individual processes (use of readymade assignments and lesson scripts, remote tracking of progress). Teachers note that digitalization saved them up to an hour every day.

A common disadvantage of the introduction of information technology in schools is the high cost and the need for retraining of teachers. Other significant disadvantages include:

Increased requirements for teachers and additional time required for retraining.

The need to develop new educational programs.

Low information culture of the teacher.

Author's opinion. Because the school cannot do without modern technology [4]

The introduction of information technology into school practice is vital, since the digital environment is a natural sphere for schoolchildren. Digital literacy today is an indispensable skill for success. Information technology can significantly improve the quality of education and the assimilation of material, and the advantages indicated in their dissemination outweigh the disadvantages.

But they are not capable and should not completely replace the teacher. The effectiveness of the introduction of digital tools and the reduction of their potential negative phenomena will largely depend on the teacher, on his ability to competently organize the lesson, activate the research and analytical skills of students.

\section{Output}

Thus, the processes of computerization of modern society are characterized by the processes of improvement and mass dissemination of modern information and communication technologies [7].

The computerization of education is one of the greatest innovations of recent decades. The penetration of modern information technologies into the field of education allows teachers to qualitatively change the content of methods and forms of teaching organization. The purpose of these technologies in education is to enhance the intellectual abilities of students in the information society, as well as humanization, individualization, intensification of the learning process and improving the quality of education at all levels of the educational system. In addition, the use of information and communication technologies allows you to optimize the management process in the field of education [6].

At present, it is customary to single out the main directions of implementation of information technologies in education: intensification of all levels of the educational process through the use of modern information technologies; student personality development; personality preparation. for a comfortable life in the information society, working to meet the social order of society.

In accordance with the tasks set, the main areas of application of information technologies are singled out: as a means and a means of teaching, as a means of creative development of a student, as a means of automating the processes of controlling the correction of psychodiagnostics. for intensification and improvement. management of an educational institution and the educational process based on the use of a modern information technology system [5]. 
Given the insufficient provision of many educational institutions with computer and telecommunication equipment, the principles of creating organizational and administrative ICT facilities should offer various educational institutions, regardless of technical equipment, equal opportunities for the provision of educational services.

\section{References}

1. XI International Conference-Exhibition 'Information Technologies in Education, Official catalog (+ CD-ROM) (MEPhI, 2016)

2. A.N. Borodulin, Intrafirm management, accounting and information technologies (PMSOFT, 2016)

3. V.M. Vdovin, Information technologies in taxation (Dashkov and Co, 2016)

4. Physical evidence. Information technology of procedural evidence (Norma, 2016)

5. Second International Conference "System Analysis and Information Technologies", Volume 1 (LKI, 2017)

6. Second International Conference "System Analysis and Information Technologies", Volume 2 (LKI, 2017)

7. M.E. Elochkin, Information technologies (Onyx-LIT, 2017)

8. A. Esipov, Informatics and information technology for school and college students (BHV-Petersburg, 2014)

9. Informatics and ICT. Methodological guide for teachers, Part 2 (Peter, 2018) 